\title{
Developing a curriculum for cardiothoracic surgical critical care: Impetus and goals
}

\author{
Hisham M. F. Sherif, MD, FACS, FICS, FACC, FAHA
}

\author{
"The future is already here. It is just not yet widely \\ distributed"
}

— William Gibson

The past 2 decades have ushered several significant changes affecting the practice of cardiothoracic surgery (CTS). An increasing number of older patients with more complex disease processes and higher acuity are presenting for surgical management. The rapid evolution in the applications of virtual reality, informatics, imaging, and devices has led to novel procedures and treatment modalities, including minimally invasive and hybrid procedures. Medical knowledge is continually expanding, providing better understanding of the natural history of diseases and the effect of various treatment modalities, through advanced monitoring technology. The practice of CTS is continually evolving to involve more active interdisciplinary collaboration among surgeons, cardiologists, radiologists, and various other clinicians. This collaboration has included novel ways of supportive measures of CTS cases in the perioperative period. ${ }^{1}$

This growing multidisciplinary collaboration has expanded beyond North America to the global CTS community at large (Joel Dunning, MD, personal communication, July 12, 2011). In addition, intersocietal and mutual recognition by the governing bodies of the specialty is fostering the creation of a truly global CTS scientific and professional community.

However, other factors during this time have had a negative impact on this goal, such as the reduction of resident work hours, a steady decline in the number of thoracic surgery applicants, and more surgeons retiring or choosing other specialties. Meanwhile, advances in the science of safety, new health care legislations, and regulatory measures have increased the focus on improved outcomes and reducing errors and cost, with significant financial reimbursement implications. ${ }^{2-4}$

From Cardiac Surgery, Christiana Hospital, Christiana Care Health System, Newark, Del.

Disclosures: Authors have nothing to disclose with regard to commercial support.

Received for publication July 13, 2011; revisions received Nov 21, 2011; accepted for publication Jan 13, 2012; available ahead of print Feb 13, 2012.

Address for reprints: Hisham M. F. Sherif, MD, FACS, FICS, FACC, FAHA, Christiana Hospital, Cardiac Surgery, 4755 Ogletown-Stanton Road, Suite 1 E

50, Newark, DE 19718 (E-mail: hsherif@christianacare.org).

J Thorac Cardiovasc Surg 2012;143:804-8

$0022-5223 / \$ 36.00$

Copyright (C) 2012 by The American Association for Thoracic Surgery

doi: $10.1016 /$ j.jtcvs.2012.01.051
This decade has also seen the emergence and rapid growth of cardiothoracic surgical critical care (CTSCC) as a robust and distinct new subspecialty with a unique scope of practice. It has gained recognition by the American Board of Thoracic Surgery in $2008^{5-7}$ and endorsement by the 2 parent organizations of CTS, the American Association for Thoracic Surgery and the Society of Thoracic Surgeons, who continue to sponsor its Symposia, postgraduate courses, and conferences organized by its dedicated organization (the Foundation for the Advancement of Cardiothoracic Surgical Critical Care). This endorsement and support continue with the American Board of Thoracic Surgery and the American Board of Surgery collaborating to create training pathways for certification in CTSCC (Valerie Rusch, MD, personal communication, May 14, 2011).

\section{IMPETUS FOR A SPECIFIC CARDIOTHORACIC SURGICAL CRITICAL CARE CURRICULUM}

The Institute of Medicine's "Crossing the Quality Chasm" 8 report includes the following among its " 10 Rules for Redesign of the Healthcare System":

- Knowledge is shared and information flows freely.

- Decision making is evidence-based.

- Safety is a system property.

- Needs are anticipated.

- Waste is continuously decreased.

This increased focus on improved outcomes in CTS can be translated into a safer, more predictable, evidencebased, cost-effective practice with less errors.

Several performance improvement strategies have emphasized the importance of the clear definition of the team function and the task to be addressed. Thus, the focus of training has shifted from the completion of a certain program to achieving competency in the knowledge base, skills, and judgment relevant to the specified areas. ${ }^{9,10}$

It has also been established that efficiently engineered systems have the least number of errors, waste the least amount of energy and resources, and produce the best outcomes in a shorter period of time. Efficiency can sometimes be described as "the right operator, with the right information, making the right decision to use the right tool to perform the right task at the right time in the right manner." In clinical terms, the promotion of a more efficient CTSCC surgical discipline means the 


\section{Abbreviations and Acronyms \\ CTS = cardiothoracic surgery \\ $\mathrm{CTSCC}=$ cardiothoracic surgical critical care}

appropriately educated and trained surgeon, equipped with the best available evidence-based information, formulating and leading the implementation of the correct management plan within the specific, relevant environment of CTSCC.

Although recent studies have demonstrated the improved outcomes when CTS-trained surgeons assume a leadership position in the practice of CSTCC, ${ }^{11,12}$ there remains a number of significant issues affecting this goal:

- The decreasing number of cardiothoracic surgeons.

- The decreased attractiveness of CTSCC as a specialty because of the reluctance to pursue a role as an "intensivist" with no operative duties. Cardiothoracic surgeons in training consider CTSCC as a small part of their education, less important than technical prowess.

- The lack of uniform, evidence-based, specialty-specific practice guidelines for CTSCC among different institutions and practitioners, in contrast with general critical care.

- The lack of a comprehensive, encompassing set of guidelines for clinical practice in the various areas of CTS, for example, general thoracic, combined cardiothoracic, adult cardiovascular, or heart failure surgery.

- The paucity of dedicated, specialty-specific staff: In academic centers, the responsibility for CTSCC cases usually falls on CTS/heart failure surgery/transplant residents or fellows, "visiting fellows," or general surgery residents rotating on the CTS service. Because of the restrictions on work hours, nurse practitioners and physician assistants have also been involved in this area of practice. In addition, the presence of residents and fellows is seen as a "temporary" staffing option, with minimal or no likelihood of pursuing a career in this field. In nonacademic centers, on the other hand, the attending cardiothoracic surgeon is primarily the main decisionmaker for CTSCC cases. General critical care specialists ("intensivists"), nurse practitioners, and physician assistants often are shouldering a major part of this responsibility.

- The above-mentioned factors apply not only to surgeons but also to other clinicians in CTSCC, such as critical care nurses, clinical nurse specialists, and nurse practitioners. These practitioners have an essential role in the specialty and face the same challenges and issues as surgeons, which often drive them away from the specialty to seek other careers. It has been a consistent goal of the Foundation for the Advancement of Cardiothoracic
Surgical Critical Care organization to engage these groups of clinicians in the emerging specialty, because it matures into a true multidisciplinary team-based clinical area (Nevin Katz, MD, personal communication, September 30, 2010).

\section{PRINCIPLES OF THE CURRICULUM}

CTS can be defined as the discipline involved in the surgical management of cardiac or pulmonary dysfunction or failure, specifically, correction of anatomic abnormalities, amelioration of functional abnormalities, and replacement of the failing organ.

The following topics represent the basic principles of CTSCC management and the basic framework for didactic education training and qualification for the cardiothoracic critical care surgeon:

1. Initial recovery from surgery: A significant experience in managing critically ill surgical patients is thus required, especially in areas common to both general surgical critical care and CTSCC. A required period of training in general surgery, as recognized by such organizations as the American Board of Surgery, the American or Royal College of surgeons, or their equivalents, can thus be one of the requirements for eligibility for the certification examination.

2. Stable/optimal native cardiovascular or pulmonary system performance: This is the heart of the management process in the CTSCC environment. The surgeon must be thoroughly knowledgeable, competent, and highly skilled in understanding the anatomic, developmental, physiologic, pathophysiologic basis for cardiac, vascular, and pulmonary disease processes. Also of paramount importance is a demonstration of a comprehensive understanding and adequate hands-on experience in the operative management of such diseases.

This particular knowledge base must also include the understanding of the preoperative status of the target organ systems, that is, the cardiovascular and pulmonary system, the effect of the disease on the other organ systems, the planned or expected impact of the surgical procedure on the course of the disease and the patient as a whole, and the expected risks and complications in the postoperative period and their impact on the longevity and quality of life of the patient.

A period of specialized CTS training (residency or fellowship) with exposure to different disciplines of CTS practice as recognized by the CTS parent organizations (American Board of Thoracic Surgery, American Association for Thoracic Surgery, Society of Thoracic Surgeons, European Association for Cardiothoracic Surgery, or their equivalents) thus becomes one of the requirements for eligibility for the certification examination. 
TABLE 1. Examples of core competency areas in the management of cardiothoracic surgical critical care patients

Monitoring and diagnostics

Hemodynamic monitoring

Imaging modalities

Systems management

Neurologic

Cardiovascula

Vascular access

Pulmonary

Gastrointestinal

Renal

Endocrinology

Infection control

Hematology
Arterial lines

Central venous catheters

Swan-Ganz catheter

Direct intracardiac lines

Pulse oximetry

Urinary catheter

Intracavitary temperature probe

Cerebral oximetry

Transcranial Doppler

Evoked response potential sensors

Electrocardiogram

Electroencephalogram

Radiography

Transthoracic echocardiography/transesophageal echocardiography

Computed tomography

Magnetic resonance imaging

Level of consciousness

Short- and long-term sedation

Agitation/restraints

Focal deficits, mental state

Psychologic/psychiatric state

Determinants of cardiac performance: Rhythm/dysrhythmia management, rate/pacing, preload/filling pressures

Afterload/SVR/PVR/vasopressors/vasodilators

Contractility/inotropes/chronotropes

Tiered plan for low cardiac output syndrome

Need for MCS/IABP, ECMO/ECLS/other MCS

Tamponade (pericardial/sternal)

Bleeding/cardiothoracic drainage/take-back/open situation

Code Blue/BLS/ACLS, CPS

Central lines/arterial lines/SG catheter/introducers, sheaths/PICC lines

Capacity for spontaneous respiration, weaning parameters, extubation/oxygen

supplement/weaning/CPAP and BiPAP

Pulmonary congestion/edema

Additional or long vent support: risks/precautions/reintubation/tracheostomy

Ventilatory strategy: types/selection/management

ECMO consideration/criteria/management

Pleural space: air leaks/pneumothorax/pleural effusions/thoracentesis/chest tube placement

Capacity for independent feeding: level of consciousness, aspiration risk, swallowing integrity

Motility issues: acute gastric dilatation/constipation/ileus/

obstruction/intestinal ischemia

Feeding strategy: diet types/feeding routes: NGT/PEG/TPN/PPN

UOP/oliguria/ATN/acute renal failure

Electrolyte balance, acid-base balance

Fluid balance/diuresis

Dialysis: HD/CVVHD/SLEDD/ultrafiltration

Glucose management/adrenal insufficiency/thyroid replacement/other issues

Prophylaxis, surveillance: sterility/infection precautions/catheter and lines/cultures

Therapeutic: empiric/culture-guided

Resistance/isolation: MRSA, VRE, neutropenic

Coagulopathy, DIC, transfusion strategy

Hypercoagulable state

HIT, HITT, warfarin (Coumadin, Bristol-Myers Squibb Co, Princeton, NJ), alternate anticoagulation 
TABLE 1. Continued

\begin{tabular}{|c|c|}
\hline Preventive measures & $\begin{array}{l}\text { DVT prophylaxis, } \\
\text { VAP prophylaxis, } \\
\text { decubitus prophylaxis, } \\
\text { CTS critical care fall precautions, } \\
\text { ulcer/GI bleeding prophylaxis, } \\
\text { bleeding precautions, and } \\
\text { wound care }\end{array}$ \\
\hline Ethical and social issues & $\begin{array}{l}\text { Decision-making, spokesperson, living will/advance directives, code status, DNR tiers and options, and } \\
\text { end-of-life issues } \\
\text { Quality of life }\end{array}$ \\
\hline Process issues & $\begin{array}{l}\text { Science of safety } \\
\text { Error causation and prevention } \\
\text { Teamwork and leadership }\end{array}$ \\
\hline
\end{tabular}

3. Stabilization/optimization of other major systems: Because the entire organism is dependent on the optimal function of the cardiopulmonary unit, disturbances of the function of other organs are frequent in the context of CTS. These system dysfunctions may have existed for a certain period of time preoperatively or develop anew after the surgical intervention or during the course of recovery. Table 1 provides some illustrative examples in specific areas in the CTSCC curriculum that require sufficient experience in identifying, monitoring, and managing disorders of these systems, as well as leading and coordinating a multidisciplinary approach with other specialists involved in the care of the CTS patient.

4. Promotion of independence from invasive measures and preparation for rehabilitation.

5. Prevention and management of complications. On the basis of the comprehensive understanding of all aspects of the conditions affecting the CTS patient population at hand, strategic planning and management of an integral pathway toward recovery and return to a meaningful, dignified quality of life are necessary.

\section{GOALS AND DIRECTIONS}

The concept of CTS practice as a "service line" process has been established. ${ }^{14}$ The core mission of the specialty is to provide excellent surgical care to CTS cases across the continuum of surgical management. ${ }^{13}$ Thus, the 21 st century cardiothoracic surgeon ${ }^{15}$ is no longer just an operating room technician but also a leader of the multidisciplinary team and well versed in all aspects of the process, with the responsibility and accountability for the patient's welfare that has characterized CTS throughout its history. ${ }^{16}$
In the face of the rapidly changing environment of CTS practice and the increasing competition from other specialties areas that are core CTS practice areas (eg, cardiac pacing, aortic repair, valve repair), CTS specialty and its parent organizations should rise to the challenge and ensure that our practitioners maintain an active interest and are well equipped to be competitive in all areas of practice, traditional or novel. ${ }^{17-19}$

On the basis of the documented improved outcomes when cardiothoracic surgeons assume responsibility for the perioperative period, CTSCC should be promoted as an exclusive new practice "niche" within the CTS specialty:

- The surgeon's involvement in all aspects of the process should be emphasized, as opposed to traditional focus on the technical duty alone.

- The importance of CTSCC in the process should be highlighted. It should not be delegated to non-surgeons, as is currently practiced. CTSCC and operative duties are not mutually exclusive areas of practice.

- The surgeon as a leader of a multidisciplinary team should be emphasized, as opposed to a clinical "turf war."

- Easy and clear pathways for certification and credentialing as "CTSCC surgeons" should be provided. The proposed curriculum can be integrated in the formal training and education of cardiothoracic residents and fellows, and thus they can be eligible to take the qualifying examination after completion of their program. Cardiothoracic surgeons already out of training can attend a focused, structured training course to become eligible for certification.

- This specific training and certification as condition for recruitment and practice in CTSCC should be required, instead of hiring a generic "intensivist." This will serve 
as the foundation for improved compensation and reimbursement in this capacity.

\section{CONCLUSIONS}

CTSCC has been established as a distinct subspecialty, gaining recognition from the specialty board and the parent organizations of thoracic surgery. The timing is perfect for the emergence of the robust, enlightened, and visionary leadership to steer this surgical discipline into the future and to bridge the knowledge gap that exists today in CTSCC. One of the essential requirements for such a successful leadership is to establish a comprehensive, adaptable, flexible state-of-the-art curriculum as a foundation for the didactic skill and practice knowledge base for cardiothoracic surgeons in leadership roles in CTSCC with a primary focus on knowledge and competency as opposed to time spent in training. Determining the eligibility to enroll in a training program for CTSCC and for credentialing and certification for cardiothoracic surgeons already in practice in this particular specialty becomes of paramount importance in attracting surgeons to this specialty, thus creating a critical mass for its members (Nevin Katz, MD, personal communication, May 8, 2011). Because of the unique nature of the specialty, currently established guidelines of other surgical societies for education, training, credentialing, and certification may be insufficient or inapplicable.

Furthermore, developing clear guidelines for training and certification will eventually have an impact on the performance and quality metrics of surgeons, as well as other clinicians, which may affect their compensation and reimbursement.

By taking a visionary leadership position in developing such a curriculum, the parent organizations and sponsors of CTSCC will further enhance the growth of a robust, modern, global, and independent subspecialty to meet the societal, scientific, and technologic challenges and demands of a new era.

\section{References}

1. Katz NM. CT critical care: challenges and developments. AATS/STS Cardiothoracic Critical Care Symposium. The 91st meeting of the American Association of Thoracic Surgery, May 8, 2011, Philadelphia, PA.

2. Williams TE, Sun B, Ross P, Thomas A. A formidable task: population analysis predicts a deficit of 2000 cardiothoracic surgeons by 2030 . J Thorac Cardiovasc Surg. 2010;139:835-40

3. Damian McNamara. Program directors cite reasons for residency drop. Thoracic Surgery News, March/April 2008. Available at: http://www.thoracicsurgerynews. com/fileadmin/content_images/aats/issue_pdfs/2008_Issues/Thoracic-SurgeryNews-March-April\%202008.pdf. Accessed January 23, 2012.

4. Council on Graduate Medical Education. Physician Workforce Policy Guidelines for the US for 2000-2020. Rockville, MD: US Department of Health and Human Services; 2005.

5. Katz NM. The emerging specialty of cardiothoracic surgical critical care: the leadership role of cardiothoracic surgeons on the multidisciplinary team. J Thorac Cardiovasc Surg. 2007;134:1109-11

6. Katz NM. The evolution of cardiothoracic critical care. J Thorac Cardiovasc Surg. 2011;141:3-6.

7. ABTS adopts two new resolutions. Thoracic Surgery News. November/ December 2008. Available at: http://www.thoracicsurgerynews.com/fileadmin/ content_images/aats/issue_pdfs/2008_Issues/Thoracic-Surgery-News-Nov-Dec \%202008.pdf. Accessed January 23, 2012.

8. Crossing the quality chasm: a new health system for the 21 st Century. National Academy Press. March 2001. Available at: http://www.nap.edu/books/ 0309072808/html. Accessed January 23, 2012.

9. Europe Japan Centre. Kaizen Strategies for Improving Team Performance. In: Colenso M, ed. London: Pearson Education Limited; 2000.

10. Liker S, Meier D. The Toyota Way Fieldbook. New York: McGraw-Hill; 2006.

11. Stamou SC, Camp SL, Stiegel RM, Reames MK, Skepper E, Watts LT, et al. Quality improvement program decreases mortality after cardiac surgery. J Thorac Cardiovasc Surg. 2008;136:494-9.

12. Kumar K, Zarychanski R, Bell DD, Manji R, Zivot J, Menkis AH, et al. The impact of 24-hour in-house intensivists on a dedicated cardiac surgery intensive care unit. Ann Thorac Surg. 2009;88:1153-61.

13. Cohn LH. Update on the cardiovascular and thoracic service-line concept. J Thorac Cardiovasc Surg. 2008;136:1403.

14. Gardner TJ. Our heritage and our future. J Thorac Cardiovasc Surg. 2002;124: 649-54.

15. Cohn LH. What the cardiothoracic surgeon of the twenty-first century ought to be. J Thorac Cardiovasc Surg. 1999;118:581-7.

16. Crawford FA. Thoracic surgery education: responding to a changing environment. J Thorac Cardiovasc Surg. 2003;126:1235-42.

17. Rao C, Patel V, Ibrahim M, Ahmed K, Wong KA, Darzi A, et al. Leadership in cardiac surgery. Eur J Cardiothorac Surg. 2011;39:905-11.

18. Cohn LH. Evidence-based cardiac surgery. J Thorac Cardiovasc Surg. 2006;132: 457-8.

19. Cohn LH. The times they are a-changin'. J Thorac Cardiovasc Surg. 2010; 140:3-4. 